Document downloaded from:

http://hdl.handle.net/10251/59883

This paper must be cited as:

Presenda, A.; Salvador Moya, MD.; Penaranda-Foix, FL.; Moreno, R.; Borrell Tomás, MA. (2015). Effect of microwave sintering on microstructure and mechanical properties in Y-TZP materials used for dental applications. Ceramics International. 41(5, Part B):7125-7132. doi:10.1016/j.ceramint.2015.02.025.

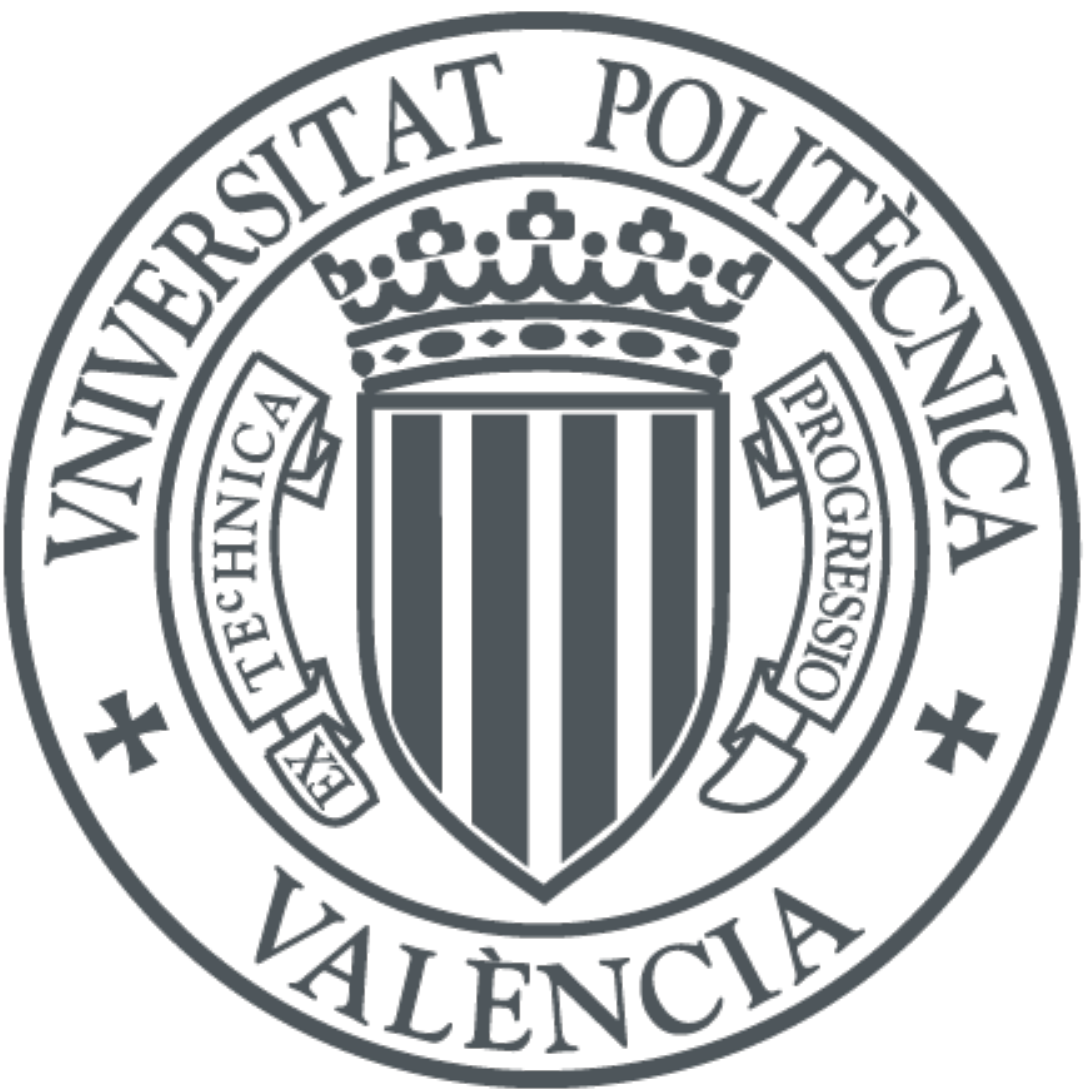

The final publication is available at

http://dx.doi.org/10.1016/j.ceramint.2015.02.025

Copyright Elsevier

Additional Information 


\title{
Effect of microwave sintering on microstructure and mechanical properties in Y-TZP materials used for dental applications
}

\author{
Álvaro Presenda ${ }^{1}$, María D. Salvador ${ }^{1}$, Felipe L. Peñaranda-Foix ${ }^{2}$, Rodrigo Moreno ${ }^{3}$ \\ Amparo Borrell ${ }^{1 *}$ \\ ${ }^{1}$ Instituto de Tecnología de Materiales (ITM), Universidad Politécnica de Valencia, Camino de \\ Vera s/n, 46022, Valencia, Spain \\ ${ }^{2}$ Instituto de Aplicaciones de las Tecnologías de la Información y de las Comunicaciones \\ Avanzadas (ITACA), Universidad Politécnica de Valencia, Camino de Vera s/n, 46022, \\ Valencia, Spain \\ ${ }^{3}$ Instituto de Cerámica y Vidrio (ICV), Consejo Superior de Investigaciones Científicas (CSIC), \\ E-28049 Madrid, Spain
}

*Corresponding author at: Instituto de Tecnología de Materiales (ITM), Universidad Politécnica de Valencia, Camino de Vera s/n, 46022, Valencia, Spain. Tel.: +34963877007; Fax: +34963 877629. E-mail address: aborrell@upv.es (A. Borrell)

\begin{abstract}
The aim of this work is to study the application of microwave sintering to consolidate yttria-stabilized zirconia polycrystalline (Y-TZP) ceramics commonly applied in dentistry, so as to obtain highly dense materials and fine microstructure with shorter sintering cycles. Three Y-TZP materials are considered: two commercially available for dental applications and one laboratory studied powder. Microwave sintering was carried out at 1200 and $1300{ }^{\circ} \mathrm{C}$ for $10 \mathrm{~min}$ and conventional sintering at 1300 and $1400{ }^{\circ} \mathrm{C}$ for 2 h. Relative density, Vickers hardness and fracture toughness values for sintered samples were determined. Microwave sintering results, generally, in improved mechanical properties of the materials in terms of hardness and fracture toughness compared to conventional sintering and, in some cases, at lower sintering temperatures. A finer grain microstructure (final grain size $<250 \mathrm{~nm}$ ) was obtained with microwave sintering for both commercial materials. Fracture toughness values differ significantly between sintering techniques and chosen parameters. These results suggest that
\end{abstract}


microwave heating can be employed to sinter Y-TZP commercial ceramics for dental applications obtaining improving the mechanical properties of the materials with a very important time and energy consumption reduction.

Keywords: Y-TZP materials; Microwave sintering; Mechanical properties; Microstructure; Dental applications

\section{Introduction}

Biomaterials could be defined as "implantable materials that perform their function in contact with living tissues". Biomaterials and tissue engineering sciences aim to develop materials, which can be implanted in the human body to replace damaged tissues. Depending on the function to perform, they can be manufactured from very different materials. If we focus on functional artificial biomaterials, the choice has to be made among metals, polymers and ceramics. Each group exhibits some a priori advantages and drawbacks. Ceramics, for instance, are the most biocompatible materials and can be obtained with biostable, bioactive or bioresorbable properties, but their main drawbacks are their hardness and fragility.

Y-TZP materials have become increasingly important in the last few decades as biomaterials for dental restorations and implants. Due to their superior mechanical properties, biocompatibility with human tissue and enhanced optical properties, these materials have become widely applied commercially and its characteristics profoundly studied. Very fine-grain microstructures may be obtained (particle size $<0.5 \mu \mathrm{m}$ ) from Y-TZP powders. Regarding mechanical properties, fracture toughness and hardness values are relatively high compared to other bioceramics $\left(4-8 \mathrm{MPa} \cdot \mathrm{m}^{1 / 2}\right.$ and $>12 \mathrm{GPa}$, respectively [1]) and fracture strength values range between 900 and $1200 \mathrm{MPa}$. According to Guazzato et al. [2], this mechanical behavior allows them to satisfy the requirements necessary for dental applications. Y-TZP materials contain between 1.5 and $3.5 \mathrm{~mol} \% \mathrm{Y}_{2} \mathrm{O}_{3}$ in solid solution as phase stabiliser because this range allows for almost $100 \%$ tetragonal $(t)$ phase content. The high fracture toughness values of Y-TZP ceramics are due to the strengthening that results when a spontaneous phase transformation from $t$ to monoclinic $(m)$ zirconia occurs as a crack propagates through the material, where the $m$-phase particles that have been transformed surround and enclose the crack inhibiting its growth, a mechanism known as transformation toughening [3]. 
Mechanical properties and microstructure of Y-TZP sintered materials are strongly influenced by the degree of densification and grain nucleation that result due to the sintering process. This is, in turn, determined by the heating mechanisms that take place within the material. Current commercial sintering of ceramic dental materials, such as Y-TZP, is based on conventional heat transfer mechanisms: conduction, convection and radiation. In this case, heat is generated from heating elements and a temperature gradient arises, as heat is transferred from the surface to the material's core. This method, however, requires long processing times. As a consequence, grain broadening occurs [4], which leads to a decrease in the final mechanical properties of the material [5,6]. It also requires a high energy consumption to reach such high temperatures and maintain it for long periods of time (around $2 \mathrm{~h}$ or more) if fully-dense materials are desired.

Currently, innovative sintering methods are being explored and studied in order to modify densification mechanisms that may improve the microstructure and mechanical properties of sintered materials and also, is very important to reduce time fabrication of these materials. Two main stages have been recognized during the sintering process: densification and grain growth [7]. The main purpose for modifying sintering mechanisms is to obtain relative densities close to theoretical values, while maintaining a controlled, but limited, grain growth [8]. Also, optimization of the process by reducing the sintering time to decrease energy consumption and/or increasing heating rates is important aspects that are being considered [9]. As a consequence, in order to improve the sintering process novel non-conventional sintering methods have been investigated and developed.

One advantageous and useful method that allows the modification of the densification mechanisms and faster processing of Y-TZP ceramics is microwave sintering [10]. In this case, traditional heat transfer mechanisms are not the driving force for densification. Instead, it is the energy conversion of electromagnetic radiation into heat by the material itself due to the material's dielectric properties [11,12]. As the temperature rises, mass diffusion mechanisms are activated forming bridges between particles in what is known as necking, which consolidates the ceramic body. Heating profiles between microwave and conventional sintering differ greatly since, in conventional sintering, heat flows from the surface of the material to its interior. In microwave sintering, heat is generated within the material core, where particles are more constrained than on the surface. Friction among tighter particles in the bulk creates a temperature gradient where heat 
flows from the inside to the surface; in what is known as volumetric heating [13-15]. Because it is a non-contact technique, the effects of differential sintering are minimized [16], which is another advantage over conventional sintering methods, where differential densification is an important problem that arises from the slow heating rates. Previous reports [17-19] have demonstrated that with this method, highly dense materials can be obtained without substantial grain coarsening because dwell time is considerably shorter and heating rates are quite high in comparison with conventional sintering [20]. Energy consumption is also significantly reduced as a consequence of the mechanisms involve in microwave heating and the aforementioned shortening of processing times. As a result, several advantages arise including improved mechanical properties and reduced environmental impact [21,22]. Therefore, microwave sintering represents an interesting and innovative alternative to consolidating dental restorations based on Y-TZP material. Replacement these pieces are particularly costly, because, the fabrication of Y-TZP restorations is expensive and demanding due to properties of this material and the technical sensitivity. This method may provide lower costs for dental professionals and customers maintaining or even improving the quality of the final product.

Microwave systems usually employ a frequency of $2.45 \mathrm{GHz}$ for heating purposes. The energy from microwaves is transferred to materials by the interaction of the electromagnetic field with a molecular dipole. The effect of this field is ultimately determined by the material's dielectric properties. In the presence of an oscillating electric field, such as the one induced by microwaves, molecular dipoles in dielectric materials will rotate continuously in order to align with the field. Heat is generated due to the molecules' internal resistance to these rotations [23]. The rise in temperature is determined by the amount of energy absorbed in the process. The acceleration of diffusion mechanisms during sintering by the oscillating electric field has also been proposed by some authors to explain enhancement of the sintering process, in what is called a "microwave effect" [24].

The objective of this work is to correlate the microwave heating processing with the microstructure and mechanical properties and its comparison with conventional sintering for Y-TZP materials commonly utilized in the dental field and its advantages. 


\section{Materials and Methods}

Three Y-TZP materials stabilized with 3 mol\% $\mathrm{Y}_{2} \mathrm{O}_{3}$ were considered and evaluated in this work. Two are commercial zirconia materials readily available and widely utilized for dental applications, LAVA, (3M, St. Paul, Minneapolis, USA) and VITA (In-Ceram YZ, Vita Zahnfabrik, Bad Säckingen, Germany). According to manufacturer's specifications sheet, LAVA and VITA zirconia materials were supplied as a pre-sintered blocks according to the International Organization for Standardization, 1998 [25]. Samples have been cut from the pre-sintered blocks and shaped into $10 \mathrm{~mm}$-diameter cylinders. The third one is modified Y-TZP powder (TZ3YS, TOSOH, Japan), which has been prepared in the laboratory by colloidal processing optimizing its rheological behavior, thus resulting in a more homogeneous material in terms of particle size than the commercial materials. The average particle size of this powder is approximately 100 $\mathrm{nm}$. For a description of the preparation process of this powder see Reference 26.

Green samples were obtained by uniaxial compression of the powders in order to consolidate cylindrical bodies with $10 \mathrm{~mm}$ in diameter. The purpose for selecting these materials was also to compare the resulting properties of the commercial ones to those of a more adjusted and carefully prepared starting material.

Sintering of samples by the conventional method (CS) was carried out in an electrical furnace (Thermolyne type 46100, Thermo Fisher Scientific) in atmospheric conditions at two different temperatures: 1300 and $1400{ }^{\circ} \mathrm{C}$, a holding time of $2 \mathrm{~h}$ and with a heating rate of $10^{\circ} \mathrm{C} / \mathrm{min}$.

Microwave sintering (MW) of samples was performed in an experimental microwave system with a $2.45 \mathrm{GHz}$ frequency. Samples were introduced in a mono-mode, rectangular cavity that is automatically adjusted to optimize microwave absorption by the material that allows controlling the heating rates $\left(100^{\circ} \mathrm{C} / \mathrm{min}\right)$, sintering temperature $\left(1200\right.$ and $1300{ }^{\circ} \mathrm{C}$ ) and holding time (10 min). These sintering parameters were previously introduced in the control software [27]. Temperature was measured on the sample surface with the aid of an optical pyrometer previously calibrated for the selected temperatures. A silicon carbide susceptor, which acts as a hybrid-heating element, is employed in order to aid sample heating in the microwave cavity. These conditions have been selected based on previous studies in our research group, which demonstrate that under such temperatures and dwell times materials with density values close to theoretical can be obtained [19,22]. 
Densification of the sintered samples was evaluated in terms of relative density and has been determined by Archimedes method, following ASTM-C-373 Standard. All specimens were mirror polished for further characterization. Mechanical properties were evaluated via micro-indentation techniques. Vickers hardness, $H_{v}$, values were measured applying loads of $0.5 \mathrm{Kg}$ for $10 \mathrm{~s}$ with a Shimadzu HMV-20 micro-indenter. 25 measurements have been carried out in each sample. $K_{I C}$ values were calculated by measuring the cracks induced by applying loads of $2 \mathrm{~kg}$ for $10 \mathrm{~s}$ with an image analysis program and utilizing the equation proposed by Niihara et al. [28]. 10 measurements have been performed in each sample. Microstructural analysis was carried out by thermally etching the samples at $100{ }^{\circ} \mathrm{C}$ below the sintering temperature. Once etched, samples were prepared for Field Emission-Scanning Electron Microscopy (FE-SEM, Gemini Ultra 55 model, Zeiss). Grain size was measured from the micrographs with an image analysis program. The grain size values presented correspond to the average of 50 grains measured in each sample.

\section{Results}

Table 1 summarizes the sintering conditions and the final grain size obtained for all samples sintered by microwave (MW) and conventional sintering (CS).

\section{Densification}

Relative density values for all samples sintered via microwave and conventional sintering are shown in Figure 1. Green density of pre-sintered blocks of zirconia commercial (LAVA and VITA) is around $40 \%$ of theoretical density.

LAVA material sintered by MW presents high relative density $>99 \%$ of the theoretical density for both sintering temperatures. MW sintering provides the highest relative density value at a sintering temperature of $1200^{\circ} \mathrm{C}$, even higher than $\mathrm{CS}$ at $1400{ }^{\circ} \mathrm{C}$. For VITA material, the relative density values obtained are low for both sintering techniques at lower temperatures, while relative density increases substantially when sintering temperature is increased by $100^{\circ} \mathrm{C}$ in both cases. TOSOH material also shows differences as the sintering temperature is increased by CS. MW sintering at $1200{ }^{\circ} \mathrm{C}$ and CS at $1400{ }^{\circ} \mathrm{C}$ show high relative density values. This demonstrates that microwave sintering provides a high degree of densification at lower sintering temperatures and shorter cycle times. 


\section{Mechanical properties}

Regarding mechanical properties, $H_{v}$ and $K_{I C}$ values, for both sintering methods are presented in Figures 2 and 3, respectively.

For LAVA material, $H_{v}$ values are between 12.7 and $14.0 \mathrm{GPa}$. In both sintering techniques, $H_{v}$ values do not change significantly after increasing sintering temperature. For VITA, $H_{v}$ values are very similar to those obtained for LAVA, ranging from 12.9 to 14.1 GPa and with no significant changes as sintering temperature is increased.

In the case of TOSOH material, the highest $H_{v}$ values of $14.7 \mathrm{GPa}$ are obtained for MW sintering. In CS, there is no significant variation in the $H_{v}$ values when increasing the sintering temperature from 1300 to $1400{ }^{\circ} \mathrm{C}$.

The facture toughness, $K_{I C}$, values for samples sintered by MW are higher than those for CS in LAVA and TOSOH. For MW and CS, $K_{I C}$ values are very close to each other for both temperatures. Regarding fracture toughness of VITA, an important difference in $K_{I C}$ values exists. $\mathrm{MW}$-sintered samples have lower $K_{I C}$ values, around $4.0 \mathrm{MPa} \cdot \mathrm{m}^{1 / 2}$, than those sintered by the conventional method, which are $>5.0 \mathrm{MPa} \cdot \mathrm{m}^{1 / 2}$. In the case of TOSOH material, the best value obtained corresponds to sample sintered at $1300{ }^{\circ} \mathrm{C}$ by MW.

\section{Microstructure and grain size}

As can be seen in Figure 4, the microstructure of LAVA material reveals significantly different grain sizes for samples sintered under different conditions. For MW-sintered samples, the average grain size is smaller (146 and $162 \mathrm{~nm}$ for 1200 and $1300{ }^{\circ} \mathrm{C}$, respectively) than CS samples (238 and $343 \mathrm{~nm}$ for 1300 and $1400{ }^{\circ} \mathrm{C}$, respectively). As sintering dwell times are shortened and heating rates are increased in microwave sintering, grain coarsening is substantially inhibited resulting in a finer microstructure. The wide range of initial particle size that is characteristic of this material in particular is also reflected on the significant variations in grain sizes that occur in the microwavesintered sample at 1200 and $1300{ }^{\circ} \mathrm{C}$. In conventional sintering, however, longer sintering times and slower heating rates allow for the consolidation of bigger particles with a more homogeneous size distribution. As a result, the standard deviation values of 
the average grain sizes found in microwave-sintered samples are bigger than their conventionally sintered counterparts.

FE-SEM micrographs for VITA material are shown in Figure 5. The average grain size of the MW-sintered samples (173 and $186 \mathrm{~nm}$ for 1200 and $1300{ }^{\circ} \mathrm{C}$, respectively) is still smaller than the average grain size for CS samples (229 and $286 \mathrm{~nm}$ for 1300 and $1400{ }^{\circ} \mathrm{C}$, respectively). Average grain size changes with sintering temperature and also with the method employed due to the different heating mechanisms that take place and processing times that are required.

Figure 6 shows FE-SEM micrographs for TOSOH material samples. The average grain size of MW-sintered samples is $174 \mathrm{~nm}$ for $1200^{\circ} \mathrm{C}$ and $194 \mathrm{~nm}$ for $1300{ }^{\circ} \mathrm{C}$, while that of CS samples is $203 \mathrm{~nm}$ and $199 \mathrm{~nm}$ for 1300 and $1400{ }^{\circ} \mathrm{C}$, respectively. This means that the difference in grain size between MW and CS samples is less than $30 \mathrm{~nm}$.

\section{Discussion}

The three materials processed and characterized in this study have provided relevant results regarding the behavior of Y-TZP materials under different sintering conditions. LAVA material sintered via MW heating shows a higher degree of densification (99.1 $\%$ ) compared to CS $(97.7 \%)$ at the same sintering temperature of $1300{ }^{\circ} \mathrm{C}$, in a considerably shorter amount of final sintering time, which is $10 \mathrm{~min}$ for MW instead of $2 \mathrm{~h}$ for CS. In other words, while the sintering time required to achieve relative densities above $>97 \%$ is 360 min using CS, the MW leads to high dense specimens in only 40 min. It is important to note that the final economic cost is very significant.

When comparing $H_{v}$ values of both sintering methods at the same sintering temperature $\left(1300{ }^{\circ} \mathrm{C}\right)$, the MW value $(12.7 \mathrm{GPa})$ is lower than the CS value $(13.6 \mathrm{GPa})$. These results contrast with those found in the literature [8], where it has been determined that Y-TZP materials sintered via MW heating at this same temperature result in higher $H_{v}$ values than those sintered by CS. To explain the results that were obtained, it is important to consider other factors, such as the sintered material not being homogeneous after the sintering process. This can be observed in the error value corresponding to this material sintered conventionally at $1300{ }^{\circ} \mathrm{C}$, where the error range is quite significant. Since the material was obtained as a pre-sintered block, there was no 
complete control of the starting material and it is possible that block was not homogeneous when provided.

$K_{I C}$ values determined for LAVA demonstrate that MW sintering results in higher values at both sintering temperatures than those of CS. By directly comparing samples sintered at $1300{ }^{\circ} \mathrm{C}$ by both methods, it is possible to determine that $\mathrm{MW}$ sintering improves fracture toughness of this material $\left(7.0 \mathrm{MPa} \cdot \mathrm{m}^{1 / 2}\right.$ for $\mathrm{MW}$ vs. $6.2 \mathrm{MPa} \cdot \mathrm{m}^{1 / 2}$ for $\mathrm{CS})$. These results coincide with those found in other studies under similar conditions, such as those of Guazzato et al. [29] and Inokoshi et al. [30].

Grain size variation in LAVA material is quite significant, almost $80 \mathrm{~nm}$ when comparing MW sintering and CS at the same sintering temperature (Fig. $4 \mathrm{~b}$ and $4 \mathrm{c}$ ). This behavior may be attributed to the material being obtained as a pre-sintered block, where the differences in grain size became quite pronounced due to processing under different sintering conditions. In a pre-sintered material, particles have already formed necks among each other and, as dwell time is increased, they are able to consolidate larger particles. Also, the fact that two different heating mechanisms occur plays a significant role. In CS, grain boundaries heat first, which means that the regions in contact with other grains are hotter and activate mass diffusion among the grains quite rapidly. In contrast, MW heating is a volumetric type of heating and, in this case, the grains' cores are heated first creating a temperature gradient that allows heat flow from the inside of the material to the grain boundary. As a consequence, one possibility is that the mass diffusion among particles at the grain boundaries occurs slower than for CS and smaller grains are obtained.

Additionally, heating rates also have a direct effect in the resulting microstructure. For the MW-sintered material, a heating rate of $100^{\circ} \mathrm{C} / \mathrm{min}$ was established, while for CS samples, the heating rate was $10^{\circ} \mathrm{C} / \mathrm{min}$. A lower heating rate allows more time for the grains to form wider bridges (necks), resulting in bigger particle sizes. Increasing temperature for both sintering methods also has an effect in the microstructure. Samples sintered at lower temperature result in smaller grain sizes for both techniques, as can be seen in the FE-SEM micrographs of Figure 6.

The $K_{I C}$ values measured for VITA material via MW sintering contrast with those obtained for LAVA, since the values of VITA are significantly lower compared to those of LAVA. This is, again, explained by the consolidation of bodies previous to sintering, 
where the density gradients within the sintered material might account for the lower $K_{I C}$ values of VITA.

According to the micrograph obtained in Fig. 5, there is also a significant variation in grain size between the samples sintered by MW and CS at the same temperature (1300 $\left.{ }^{\circ} \mathrm{C}\right)$. Again, this is attributed to the heating rates, sintering time and heating mechanisms involved in MW sintering, as described above for LAVA. However, these differences are not as pronounced as those observed in LAVA. The differences in grain size of VITA material samples between MW and CS are no more than $100 \mathrm{~nm}$, which is different than those of LAVA, where differences of almost $80 \mathrm{~nm}$ are observed. This is a consequence of the state of the raw material, since a pre-sintered block, LAVA and VITA, have already a previous heat treatment and particles have already been consolidated to some extent and the differences in size are more pronounced after processing.

In terms of relative density, TOSOH material shows a higher degree of densification, as well as better mechanical properties. Such a behavior was expected because the starting material is highly controlled as opposed to LAVA and VITA. Since a previous rheological study of this lab-material (TOSOH) was carried out, a more homogenous powder with no aggregate formation was obtained. When comparing sintering methods, it is observed that MW-sintered samples result in higher $H_{v}$ values than $C S$. However, the differences in $H_{v}$ tend to be less pronounced between both sintering methods than for the commercial materials. The highest $H_{v}$ value $(14.7 \mathrm{GPa})$ is obtained for MW sintering at $1200{ }^{\circ} \mathrm{C}$. This value is the highest of all materials and for both sintering methods. This means that, for this particular material, a sintering temperature above $1200{ }^{\circ} \mathrm{C}$ is not going to improve significantly $H_{v}$.

Regarding fracture toughness, $K_{I C}$ values are quite similar when comparing both sintering techniques. At $1200{ }^{\circ} \mathrm{C}$ by MW the value is the same that the material sintered at $1400{ }^{\circ} \mathrm{C}$ by CS. This is significant from the point of view of fabricated Y-TZP materials with an important reducing of time and energy.

The microstructure analysis of TOSOH material obtained at $1400{ }^{\circ} \mathrm{C}$ by CS reveals an important difference in grain size when comparing with the other commercial materials. This difference is approximately $150 \mathrm{~nm}$. Other important factor is the complete elimination of residual porosity in samples obtained by MW (Fig. 6a and 6b) and more 
uniform microstructure compared to commercial materials. In this case, this behavior may be explained by the characteristics of the starting material. As previously mentioned, TOSOH material consists of particles with no aggregates.

In general, the materials considered in this study sintered either by MW or CS has resulted in $H_{v}$ and $K_{I C}$ values that fall within the admissible range of values that are typical for Y-TZP materials found in the literature (Table 2). This table compares the mechanical properties of Y-TZP materials stabilized with $3 \mathrm{~mol} \% \quad \mathrm{Y}_{2} \mathrm{O}_{3}$ reported previously with that of the present study [31,32].

These values also comply with the requirements established by dentistry standards for fixed dental prostheses and dental implants. Since all materials are Y-TZP, it would be expected that those sintered under the same conditions (sintering method, temperature, time) resulted in very similar mechanical properties. However, notable differences exist in the presented $H_{v}$ and $K_{I C}$ values due to the fact that the starting material has been obtained from different sources and under different conditions.

\section{Conclusions}

The results obtained in this work suggest that microwave sintering, in some cases, results in better mechanical properties in terms of fracture toughness than conventional sintering. It has also been established that the TOSOH material had the highest $H_{v}$ and $K_{I C}$ values, as well as that of relative density and the least variation in average particle size when sintered at lower temperatures. This result is a consequence of the rheological study that has been previously carried out that allows for a more homogeneous starting powder free of aggregates, emphasizing the importance of the raw material. This has a direct effect on the final properties of sintered materials. The resulting microstructure

for all samples could be compared in terms of particle size. Smaller grain sizes were obtained for MW-sintered samples than for CS samples in all materials.

Overall, microwave sintering is a very good alternative for sintering and consolidating Y-TZP commercial materials for dental applications due to the resulting finer microstructure, enhanced mechanical properties and reduction in processing times and energy consumption. 


\section{Acknowledgements}

The authors would like to thank the financial support received from Universidad Politécnica de Valencia under project SP20120677 and Ministerio de Economía y Competitividad (MINECO) and co-funded by ERDF (European Regional Development Funds) through the project (TEC2012-37532-C02-01). A. Borrell acknowledges the Spanish Ministry of Science and Innovation for her Juan de la Cierva contract (JCI2011-10498) and the Generalitat Valenciana for the financial support under project GV/2014/009. A. Presenda acknowledges the Generalitat Valenciana for his Santiago Grisolía program scholarship (GRISOLÍA/2013/035). The authors would also like to acknowledge Prof. Dr. M. F. Solá from the Faculty of Medicine and Odontology at the Universidad de Valencia for supplying the commercial materials. 


\section{References}

[1] C. Piconi, G. Maccauro Zirconia as a ceramic biomaterial, Biomater. 20 (1999) 1-25.

[2] M. Guazzato, M. Albakry, S. Ringer, M. Swain, Strength, fracture toughness and microstructure of a selection of all-ceramic materials. Part II. Zirconia based dental ceramics. Dent. Mater. 20 (2004) 449-456.

[3] R.M. McMeeking, A.G. Evans, Mechanics of transformation-toughening in brittle materials, J. Am. Ceram. Soc. 65 (1982) 242-246.

[4] U. Anselmi-Tamburini, J.E. Garay, Z.A. Munir, Fast low-temperature consolidation of bulk nanometric-ceramic materials, Scrip. Mater. 54 (2006) 823-828.

[5] E.O. Hall, The deformation and ageing of mild steel: III. Discussion of results, Proc. Phys. Soc. B 64 (1951) 747-753.

[6] N.J. Petch, The cleavage strength of polycrystals, J. Iron Steel Inst. 173 (1953) 2528.

[7] A. Barba, C. Clausell, C. Felíu, M. Monzó, Sintering of $\left(\mathrm{Cu}_{0.25} \mathrm{Ni}_{0.25} \mathrm{Zn}_{0.50}\right) \mathrm{Fe}_{2} \mathrm{O}_{4}$ ferrite, J. Am. Ceram. Soc. 87 (2004) 571-577.

[8] S.S. Nightingale, D.P. Dunne, H.K. Worner, Sintering and grain growth of 3 mol\% yttria zirconia in a microwave field, J. Mater. Sci. 31 (1996) 5039-5043.

[9] C.B. Carter, M.G. Norton, Ceramic Materials Science and Engineering, ed. Springer, New York, 2007.

[10] D.S. Patil, B.C. Mutsuddy, Microwave sintering of yttria-containing tetragonal zirconia polycrystal (Y-TZP) ceramics, Bull. Mater. Sci. 17 (1994) 1441-1446.

[11] A. Goldstein, N. Travitzky, A. Singurindi, M. Kravchik, Direct microwave sintering of yttria-stabilized zirconia at 2.45 GHz, J. Eur. Ceram. Soc. 19 (1999) 20672074.

[12] S. Bodhak, S. Bose, A. Bandyopadhyay, Densification study and mechanical properties of microwave-sintered mullite and mullite-zirconia composites, J. Am. Ceram. Soc. 94 (2010) 32-41.

[13] D.D. Upadhaya, A. Ghosh, K.R. Gurumurthy, R. Prasad, Microwave sintering of cubic zirconia, Ceram. Int. 27 (2001) 415-418.

[14] D.E. Clark, D.C. Folz, J.K. West, Processing materials with microwave energy, Mater. Sci. Eng. A 287 (2000) 153-158. 
[15] J. Binner, K. Annapoorani, A. Paul, I. Santacruz, B. Vaidhyanathan, Dense nanostructured zirconia by two-stage conventional/hybrid microwave sintering, J. Eur. Ceram. Soc. 28 (2008) 973-977.

[16] R.R. Menezes, A.R.H.G. Kiminami, Microwave sintering of alumina-zirconia nanocomposites, J. Mater. Process. Tech. 203 (2008) 513-517.

[17] S.S. Park, T.T. Meek, Characterization of $\mathrm{ZrO}_{2}-\mathrm{Al}_{2} \mathrm{O}_{3}$ composites sintered in a 2.45 GHz electromagnetic field, J. Mater. Sci. 26 (1991) 6309-6313.

[18] M. Oghbaei, O. Mirzaee, Microwave versus conventional sintering: a review of fundamentals, advantages and applications, J. Alloy Compd. 494 (2010) 175-189.

[19] A. Borrell, M.D. Salvador, F. Peñaranda-Foix, J.M. Catala-Civera, Microwave sintering of zirconia materials: mechanical and microstructural properties, Int. J. Appl. Ceram. Tec. 10 (2013) 313-320.

[20] V. Tsakaloudi, E. Papazoglou, V.T. Zaspalis, Microwave firing of MnZn-ferrites, Mater. Sci. Eng. B 106 (2004) 289-294.

[21] A.A. Almazdi, H.M. Khajah, E.A. Monaco, H. Kim, Applying microwave technology to sintering dental zirconia, J. Prosthet. Dent. 108 (2012) 304-309.

[22] A. Borrell, M.D. Salvador, E. Rayón, F.L. Peñaranda-Foix, Improvement of microstructural properties of 3Y-TZP materials by conventional and non-conventional sintering techniques, Ceram. Int. 38 (2012) 39-43.

[23] E.T. Thostenson, T.W. Chou, Microwave processing: fundamentals and applications, Comp. Part A 30 (1999) 1055-1071.

[24] N.I. Joomun, J.A. Kilner, J. Wang, B. Vaidhyanathan, J.G.P. Binner, Microwave Hybrid Annealing and its Effect on Oxygen Diffusion in Yttria-Stabilized Zirconia Polycrystals, in Proc. 9th Int. Conf. on MW \& HF Heating. Loughborough, UK, 2003, pp. 405-408.

[25] International Organization for Standardization, Dental Ceramic: Amendment 1, ISO, Geneva 1998, pp. 6872.

[26] E. Rayón, R. Moreno, C. Alcázar, M.D. Salvador, F.J. Manjón, E. Jiménez-Piqué, L. Llanes, Enhanced hydrothermal resistance of Y-TZP ceramics through colloidal processing, J. Am. Ceram. Soc. 96 (2013) 1070-1076.

[27] A. Borrell, M.D. Salvador, F.L. Peñaranda-Foix, P.J. Plaza-González, B. GarcíaBaños, S. García-Nieto, Adaptive microwave system for optimum new material sintering, IEEE Conference Publications. Microwave Symposium Digest (IMS), doi: 10.1109/MWSYM.2013.6697540 
[28] K. Niihara, R Morena, D.P.H. Hasselman, Evaluation of $\mathrm{K}_{\mathrm{IC}}$ of brittle solids by the indentation method with low crack-to-indentation ratios, J. Mater. Sci. Lett. 1 (1982) 13-16.

[29] M. Guazzato, M. Albakry, M.V. Swain, J. Ironside, Mechanical properties of InCeram alumina and In-Ceram zirconia, Int. J. Prosthodont. 15 (2002) 339-346.

[30] M. Inokoshi, F. Zhang, J. De Munck, S. Minakuchi, I. Naert, K. Vanmeensel, Influence of sintering conditions on low-temperature degradation of dental zirconia, Dent. Mater. 30 (2014) 669-678.

[31] D.D. Upadhyaya, A. Ghosh, G.K. Dey, R. Prasad, A.K. Suri, Microwave sintering of zirconia ceramics, J. Mater. Sci. 36 (2001) 4707-4710.

[32] J. Wilson, S.M. Kunz, Microwave sintering of partially stabilized zirconia, J. Am. Ceram. Soc. 71 (1988) 40-41. 


\section{Figure captions:}

Figure 1. Relative density values for all zirconia materials after microwave and conventional sintering at various temperatures.

Figure 2. Vickers hardness values for all zirconia materials after microwave and conventional sintering at various temperatures.

Figure 3. Fracture toughness values for all zirconia materials after microwave and conventional sintering at various temperatures.

Figure 4. FE-SEM micrographs for LAVA material under different sintering conditions: microwave sintering for $10 \mathrm{~min}$ of holding time at: a) $1200{ }^{\circ} \mathrm{C}$ and b) $1300{ }^{\circ} \mathrm{C}$ and, conventional sintering for $2 \mathrm{~h}$ at: c) $1300{ }^{\circ} \mathrm{C}$ and d) $1400{ }^{\circ} \mathrm{C}$.

Figure 5. FE-SEM micrographs for VITA material under different sintering conditions: microwave sintering for 10 min of holding time at: a) $1200{ }^{\circ} \mathrm{C}$ and b) $1300{ }^{\circ} \mathrm{C}$ and, conventional sintering for $2 \mathrm{~h}$ at: c) $1300{ }^{\circ} \mathrm{C}$ and d) $1400{ }^{\circ} \mathrm{C}$.

Figure 6. FE-SEM micrographs for $\mathrm{TOSOH}$ material under different sintering conditions: microwave sintering for $10 \mathrm{~min}$ of holding time at: a) $1200{ }^{\circ} \mathrm{C}$ and b) 1300 ${ }^{\circ} \mathrm{C}$ and, conventional sintering for $2 \mathrm{~h}$ at: c) $1300^{\circ} \mathrm{C}$ and d) $1400^{\circ} \mathrm{C}$. 


\begin{tabular}{|c|c|c|c|c|}
\hline Material & $\begin{array}{c}\text { Sintering } \\
\text { method }\end{array}$ & $\begin{array}{c}\text { Final } \\
\text { temperature } \\
\left({ }^{\circ} \mathbf{C}\right)\end{array}$ & $\begin{array}{l}\text { Dwell } \\
\text { time } \\
\text { (min) }\end{array}$ & $\begin{array}{c}\text { Average } \\
\text { grain size } \\
(\mathbf{n m})\end{array}$ \\
\hline \multirow{4}{*}{ LAVA } & \multirow{2}{*}{ CS } & 1300 & 120 & $238 \pm 54$ \\
\hline & & 1400 & 120 & $343 \pm 43$ \\
\hline & \multirow{2}{*}{ MW } & 1200 & 10 & $146 \pm 64$ \\
\hline & & 1300 & 10 & $162 \pm 98$ \\
\hline \multirow{4}{*}{ VITA } & \multirow{2}{*}{$\mathrm{CS}$} & 1300 & 120 & $229 \pm 67$ \\
\hline & & 1400 & 120 & $286 \pm 68$ \\
\hline & \multirow{2}{*}{ MW } & 1200 & 10 & $173 \pm 49$ \\
\hline & & 1300 & 10 & $186 \pm 43$ \\
\hline \multirow{4}{*}{ TOSOH } & \multirow{2}{*}{ CS } & 1300 & 120 & $203 \pm 48$ \\
\hline & & 1400 & 120 & $199 \pm 85$ \\
\hline & \multirow{2}{*}{ MW } & 1200 & 10 & $174 \pm 67$ \\
\hline & & 1300 & 10 & $194 \pm 88$ \\
\hline
\end{tabular}

Table 1. Summary of the sintering parameters and final grain size determined for all materials after conventional and microwave sintering. 


\begin{tabular}{c|cc}
\hline Authors & $\boldsymbol{H}_{v}(\mathbf{G P a})$ & $\boldsymbol{K}_{\boldsymbol{I C}}\left(\mathbf{M P a} \cdot \mathbf{m}^{\mathbf{1} \mathbf{2}}\right)$ \\
\hline & \multicolumn{2}{|c}{ Conventional sintering } \\
\hline Guazzato et al. $^{\mathbf{2 9}}$ & $9-15$ & $3.0-8.0$ \\
Inokoshi et al. $^{\mathbf{3 0}}$ & $12-14$ & $3.0-5.0$ \\
Present study & $13-14$ & $5.0-6.5$ \\
\hline Wilson et al. $^{\mathbf{3 2}}$ & Microwave sintering \\
\hline Upadhyaya et al. $^{\mathbf{3 1}}$ & $11-12$ & 4.8 \\
Borrell et al. $^{\mathbf{9}}$ & $14-15$ & 8.6 \\
Present study & $13-15$ & 4.5 \\
\hline
\end{tabular}

Table 2. Summary of the hardness and fracture toughness values for materials studied with different authors. 

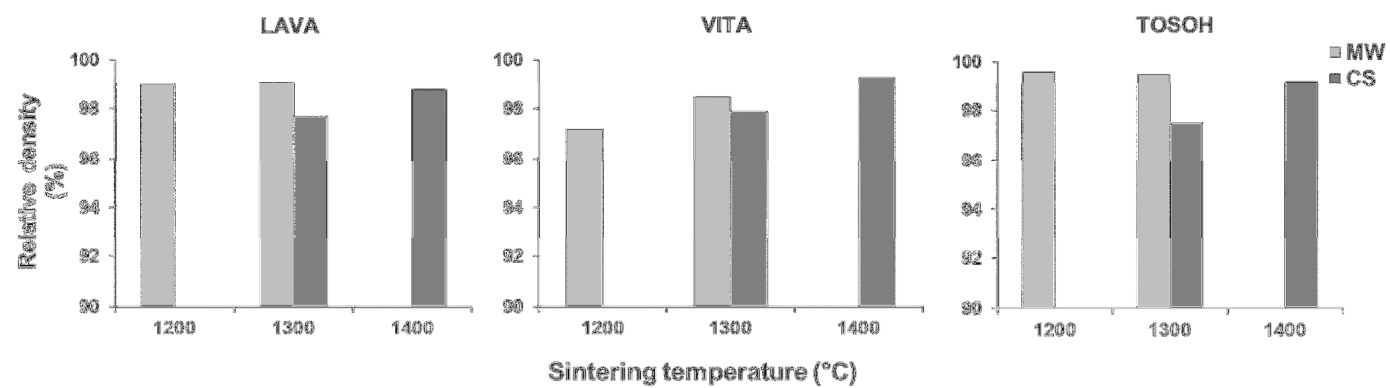

Fig 1
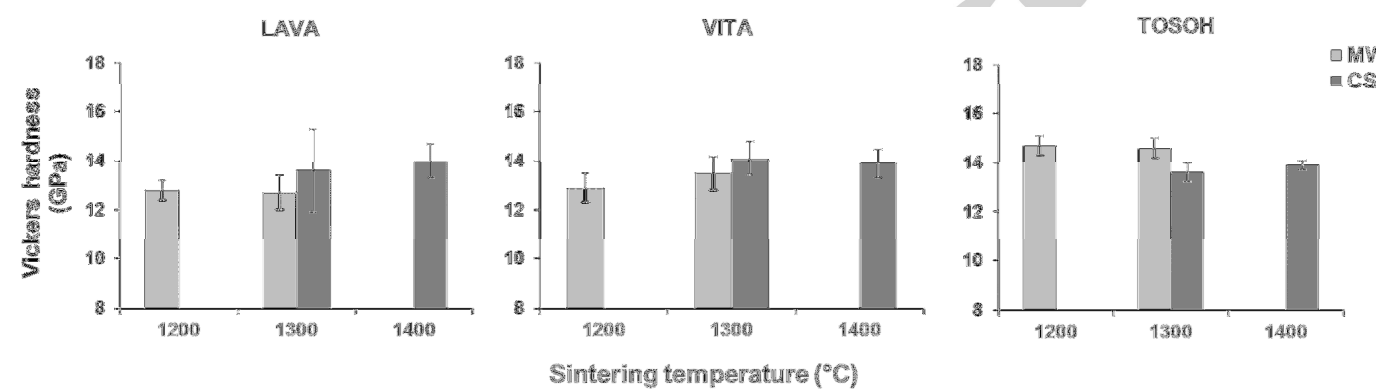

Fig 2
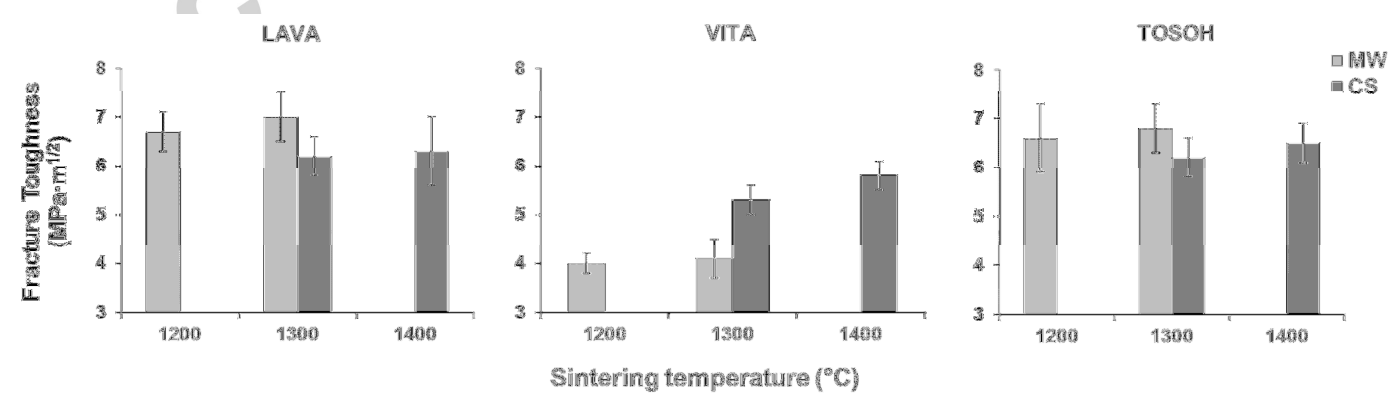

Fig 3 
Fig 4
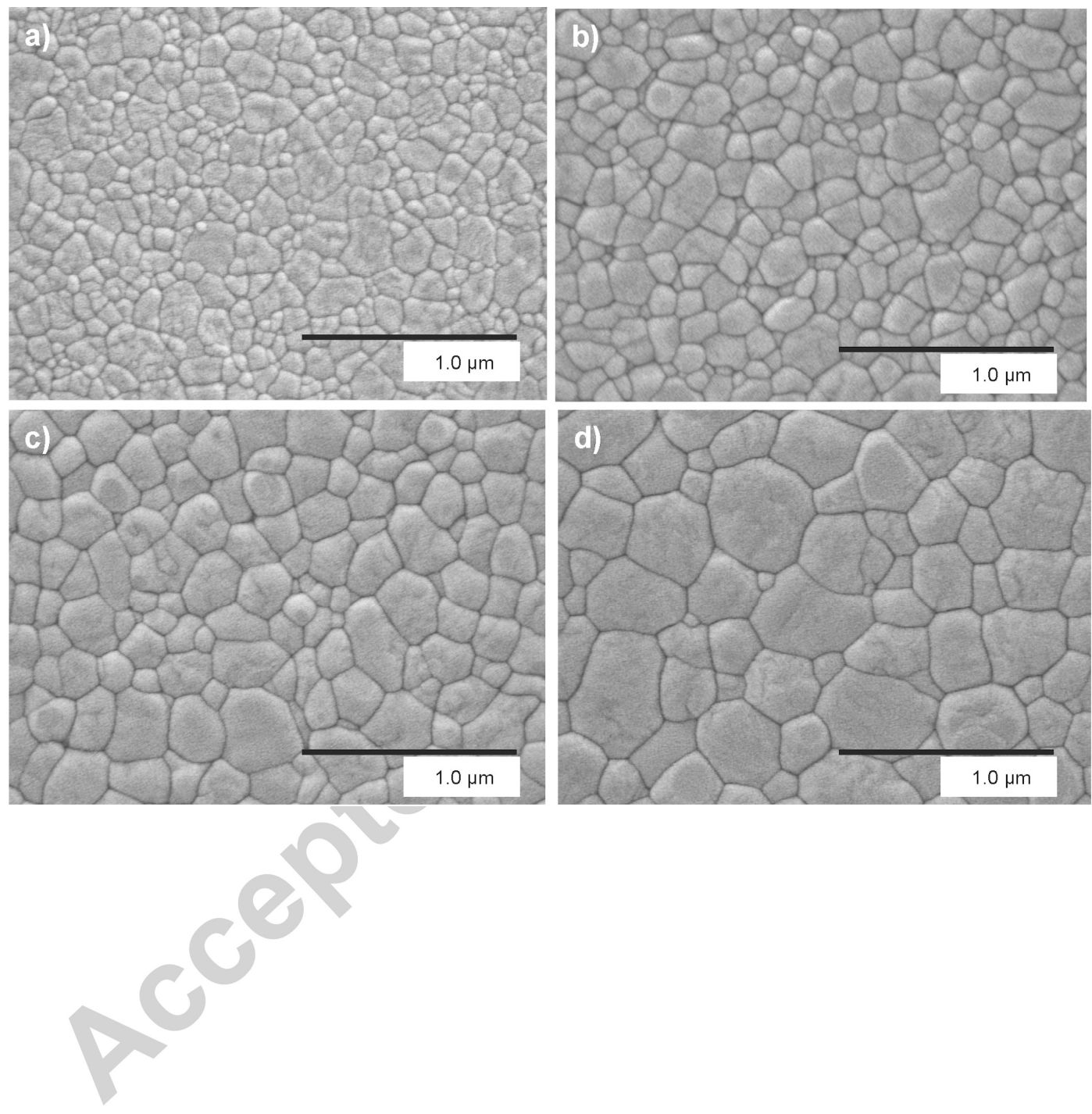
Fig 5
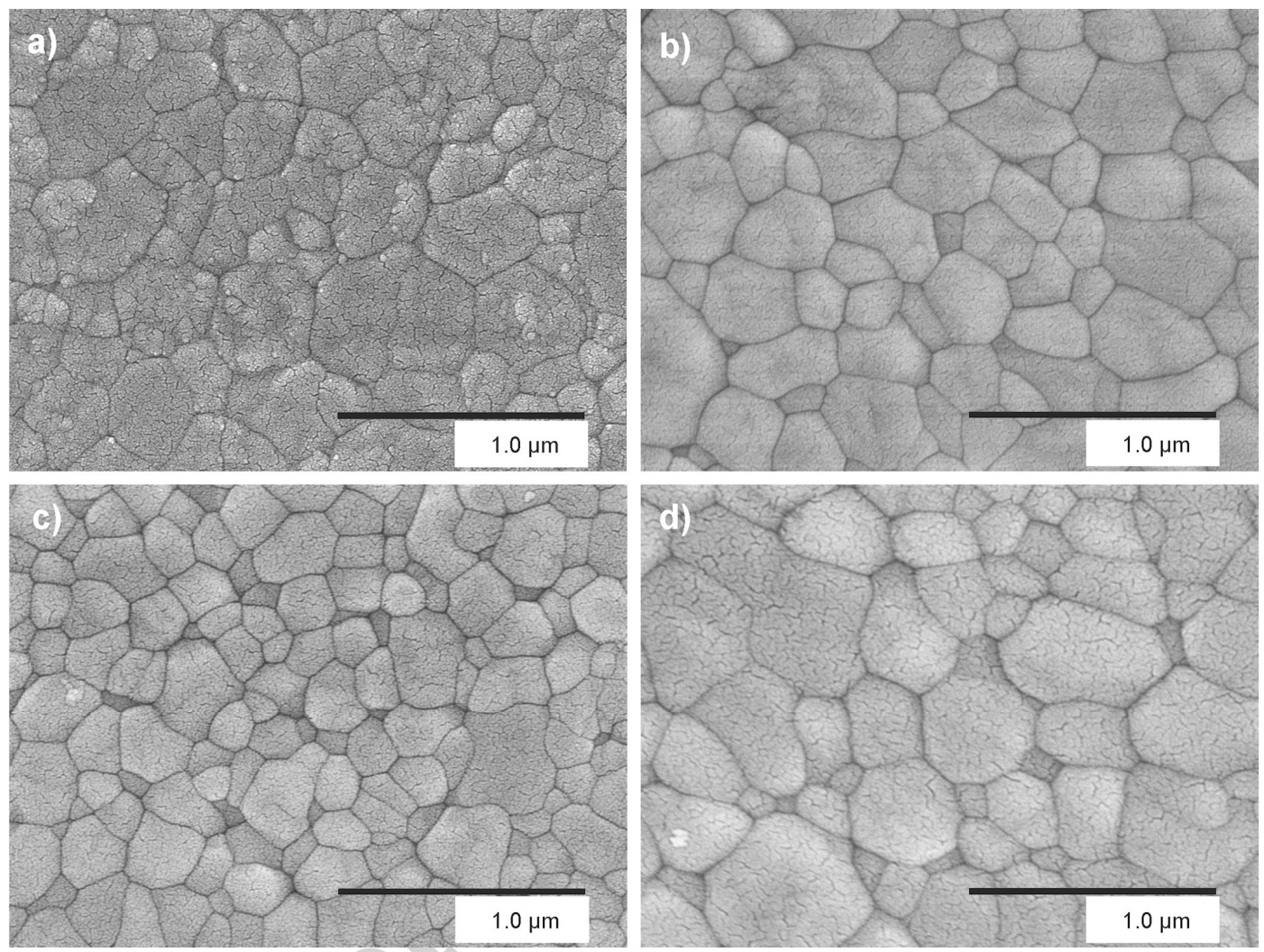
Fig 6
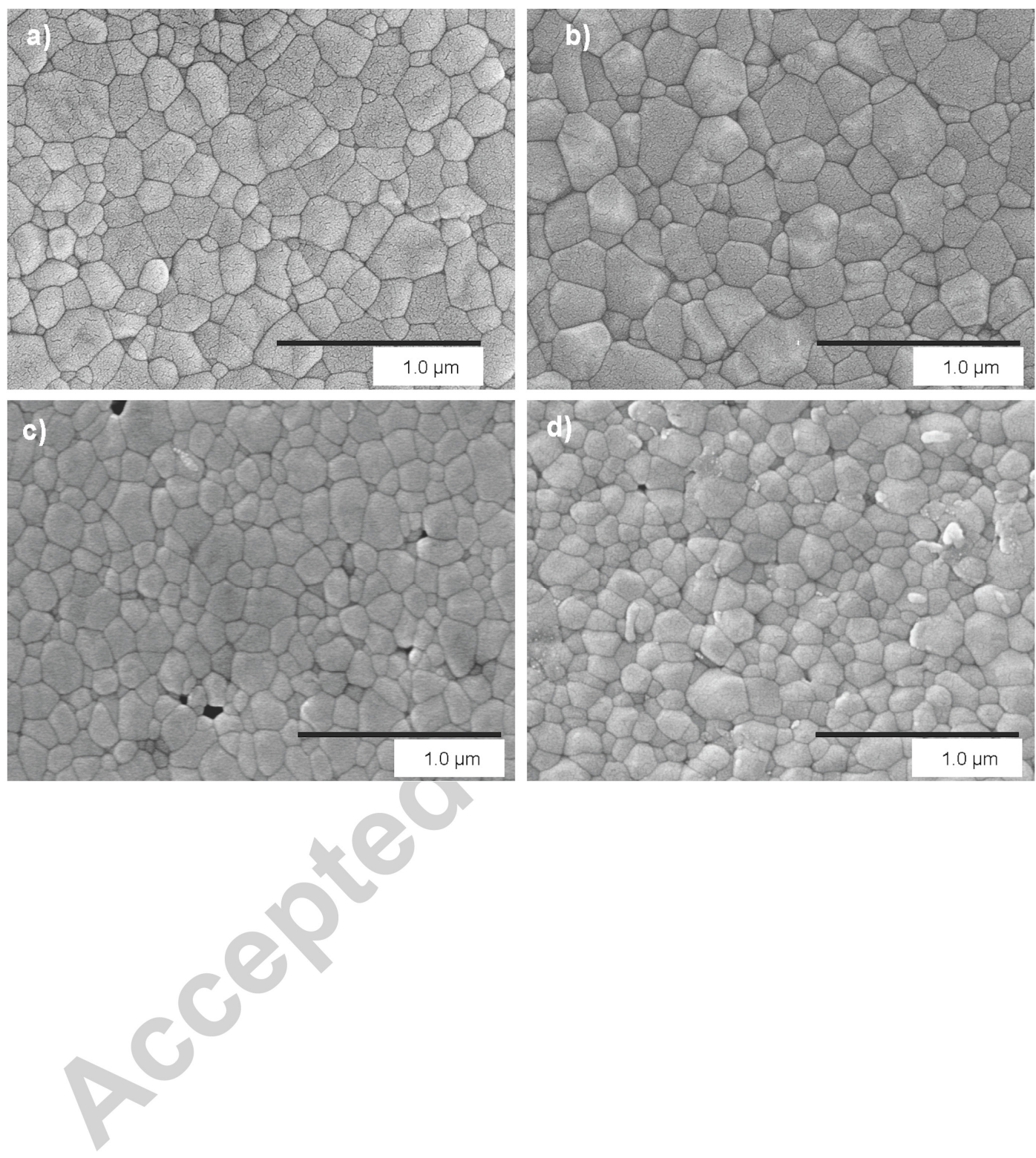